Available online at www.sciencedirect.com

SCIENCE DIRECT

Chemical Physics Letters 372 (2003) 603-607

CHEMICAL

PHYSICS

LETTERS

www.elsevier.com/locate/cplett

\title{
Carbon nanotube growth enhanced by nitrogen incorporation
}

\author{
Tae-Young Kim ${ }^{\mathrm{a}, \mathrm{b}}$, Kwang-Ryeol Lee ${ }^{\mathrm{a}, *}$, Kwang Yong Eun ${ }^{\mathrm{a}}$, Kyu-Hwan Oh ${ }^{\mathrm{b}}$ \\ ${ }^{a}$ Future Technology Research Division, Korea Institute of Science and Technology, P.O. Box 131, Cheongryang, \\ Seoul 136-791, Republic of Korea \\ ${ }^{\mathrm{b}}$ Department of Materials Engineering, Seoul National University, Shinrim-Dong, Seoul 120-749, Republic of Korea
}

Received 25 November 2002; in final form 15 March 2003

\begin{abstract}
It is well known that the growth of carbon nanotubes (CNTs) by chemical vapor deposition using a transition metal catalyst is greatly enhanced in a nitrogen environment. We show here that the enhanced growth is closely related to nitrogen incorporation into the CNT wall and cap during growth. This behavior is consistent with theoretical calculations of $\mathrm{CN}_{x}$ thin films, showing that nitrogen incorporation to the graphitic basal plane reduces the elastic strain energy for curving the graphitic layer. Enhanced CNT growth by nitrogen incorporation is thus due to a decrease in the activation energies required for nucleation and growth of the tubular graphitic layer.
\end{abstract}

(C) 2003 Elsevier Science B.V. All rights reserved.

\section{Introduction}

Synthesis and characterization of carbon nanotubes (CNTs) have been extensively studied in the last decade owing to their unique properties and potential application to nanoscale devices [1-5]. In chemical vapor deposition (CVD) processes using transition metal particles as the reaction catalyst, it is believed that the CNT forms from the saturated metal catalyst surface that resides at either the base [6-8] or the tip of a growing nanotube $[9,10]$. The CVD process has many advantages over other deposition methods, including low deposition temperature and control of the diameter of the CNT by varying the size of the metal

\footnotetext{
${ }^{*}$ Corresponding author.

E-mail address: krlee@kist.re.kr (K.-R. Lee).
}

catalyst. Furthermore, it is relatively easy to obtain vertically aligned CNTs by increasing nucleation density and the growth rate [11,12]. The microstructure of the vertically aligned CNT thus reflects the enhanced CNT growth in the CVD process.

Most previous results using the CVD process showed that the vertically aligned CNTs were obtained in $\mathrm{N}_{2}$ or $\mathrm{NH}_{3}$ gas environments, which reveals the key role of nitrogen in CNT growth. However, the environment gas has only been considered as an etching agent of the catalyst particle [13], a diluting gas to suppress excess decomposition of hydrocarbon precursor [14] or a reducing gas for the oxide layer of the catalyst surface [15]. On the other hand, Jung et al. [16] focused on the activated nitrogen that can enhance CNT growth. They compared the deposition behavior in an $\mathrm{NH}_{3}$ environment with that in a 
mixed environment of $\mathrm{H}_{2}$ and $\mathrm{N}_{2}$ with the atomic ratio $\mathrm{H} / \mathrm{N}=3$, as in $\mathrm{NH}_{3}$. They observed vertically aligned CNTs only in the $\mathrm{NH}_{3}$ environment, where the activated nitrogen could be generated by thermal decomposition of $\mathrm{NH}_{3}$. In the mixed environment, $\mathrm{N}_{2}$ acted like an inert gas and only amorphous carbon was deposited, with no CNT growth. Although this result shows that CNT growth is greatly enhanced by activated nitrogen, its role in CNT growth needs to be clarified based on systematic experimental evidence. In the present work, we show that the enhanced CNT growth results from nitrogen incorporation to the CNT wall or cap, which can reduce the elastic strain energy to form a tubular graphitic layer of CNT.

\section{Experimental}

The nanotubes were grown by using thermal decomposition of acetylene $\left(\mathrm{C}_{2} \mathrm{H}_{2}\right)$ at atmospheric pressure. Thin film (3 nm) Ni was deposited on an oxidized $\mathrm{Si}\left(\begin{array}{lll}0 & 0\end{array}\right)$ wafer by $\mathrm{DC}$ magnetron sputtering. The specimen was annealed at $800{ }^{\circ} \mathrm{C}$ for $15 \mathrm{~min}$ in a hydrogen environment to obtain uniformly distributed catalyst particles whose diameter ranged from 17 to $58 \mathrm{~nm}$. The specimen was transferred to the horizontal quartz tube reactor. Details of the reactor are given elsewhere [16]. Before loading the specimen to the reaction zone, the temperature of the reactor was increased to $950{ }^{\circ} \mathrm{C}$ in an $\mathrm{Ar}$ environment. The specimen was then pushed to the reaction zone by a loading system. If required, pretreatment was performed before the CNT deposition in $\mathrm{H}_{2}, \mathrm{NH}_{3}$ or their mixture. Carbon was deposited by adding $\mathrm{C}_{2} \mathrm{H}_{2}$ to the environment gas with the concentration of $\mathrm{C}_{2} \mathrm{H}_{2}$ ranging from 1.5 to $100 \mathrm{vol} \%$.

\section{Results and discussion}

Fig. 1a shows the cross-sectional SEM image of vertically aligned $\mathrm{CNT}$ grown for $20 \mathrm{~min}$ using $16.7 \mathrm{vol} \%$ of $\mathrm{C}_{2} \mathrm{H}_{2}$ in an $\mathrm{NH}_{3}$ environment. Before the deposition, the sample was pretreated in a pure $\mathrm{NH}_{3}$ environment for $1 \mathrm{~h}$. The diameter of the CNTs measured by high magnification SEM and
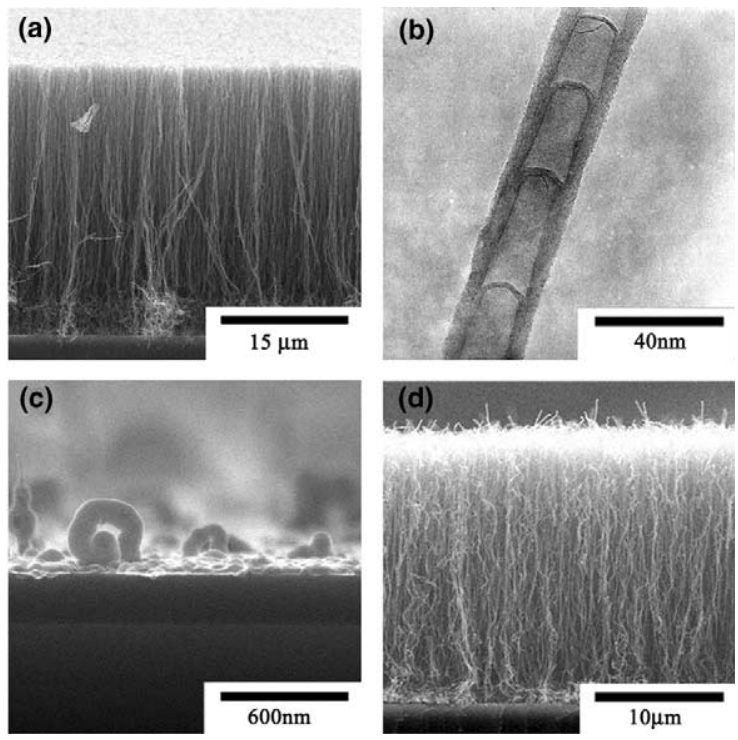

Fig. 1. SEM (a) and TEM (b) images of the CNTs deposited at $950{ }^{\circ} \mathrm{C}$ for $20 \mathrm{~min}$ in a $16.7 \mathrm{vol} \% \mathrm{C}_{2} \mathrm{H}_{2}+\mathrm{NH}_{3}$ environment after pretreatment at $950{ }^{\circ} \mathrm{C}$ for $1 \mathrm{~h}$ in an $\mathrm{NH}_{3}$ environment. (c) SEM image of amorphous carbon deposited for $20 \mathrm{~min}$ in a $16.7 \mathrm{vol} \% \mathrm{C}_{2} \mathrm{H}_{2}+\mathrm{H}_{2}$ environment after pretreatment for $4 \mathrm{~h}$ in an $\mathrm{NH}_{3}$ environment. (d) SEM image of CNTs deposited for $20 \mathrm{~min}$ in a 16.7 vol $\% \mathrm{C}_{2} \mathrm{H}_{2}+\mathrm{NH}_{3}$ environment without pretreatment.

TEM ranges from 23 to $79 \mathrm{~nm}$, which is comparable to that of the catalyst particle. The TEM microstructure of the CNT (Fig. 1b) shows that the CNT grows with 'bamboo-like' structure. Both the diameter and the TEM microstructure are consistent with the base growth model: the number of graphitic layers deposited on the catalyst surface was separated from the catalyst surface, resulting in the growth of CNT with a closed end [6-8]. The base growth model would suggest two possibilities for the role of activated nitrogen. In the present experimental condition, pretreatment in an activated nitrogen environment results in nitrogen incorporation into the catalyst surface [16]. The modified catalyst surface may change the nucleation behavior of the graphitic layer or the separation of the deposited layer from the catalyst surface to evolve the CNT structure. If this were the major role of the activated nitrogen, pretreatment in the $\mathrm{NH}_{3}$ environment would be essential for CNT growth. The other possibility is based on 
the atomic scale electron energy-loss spectroscopy (EELS) analysis of CNT showing that the nitrogen is incorporated into the CNT wall or cap in the $\mathrm{NH}_{3}$ environment [17]. If nitrogen incorporation enhances CNT growth, the nitrogen environment during growth would be a prerequisite for the vertically aligned CNT growth.

In the present work, we performed two experiments in order to verify the possibilities. In the first experiment, the sample was pretreated in an $\mathrm{NH}_{3}$ environment for $4 \mathrm{~h}$. Auger spectroscopy shows that the nitrogen was incorporated in the catalyst surface during the pretreatment. (Because of the limited spatial resolution of Auger spectroscopy, the spectrum includes compositional information on the $\mathrm{SiO}_{2}$ surface layer as well as the catalyst surface. However, the Auger spectrum analysis of the substrate without catalyst particles showed that the amount of nitrogen incorporated into the $\mathrm{SiO}_{2}$ surface layer was negligible.) After the pretreatment, $\mathrm{NH}_{3}$ gas in the reactor was replaced by the mixture of $16.7 \mathrm{vol} \% \mathrm{C}_{2} \mathrm{H}_{2}$ and $\mathrm{H}_{2}$ gas for carbon deposition. In this experimental condition, only amorphous carbon was deposited on the catalyst surface, as shown in Fig. 1c. In the second experiment, the carbon was deposited without pretreatment by using $16.7 \mathrm{vol} \%$ of $\mathrm{C}_{2} \mathrm{H}_{2}$ in an $\mathrm{NH}_{3}$ environment. Fig. 1d shows the SEM microstructure of the vertically aligned CNTs grown in the second experimental condition. The same behavior was observed when the sample was pretreated in an $\mathrm{H}_{2}$ environment. From these results, we can conclude that pretreatment in an $\mathrm{NH}_{3}$ environment is neither a sufficient nor a necessary condition for the vertically aligned CNT growth. On the other hand, an $\mathrm{NH}_{3}$ environment during growth significantly enhances CNT growth, regardless of the pretreatment condition (see Fig. 1a,d).

Fig. 2 shows the change in morphologies of the deposited carbon when the concentration of $\mathrm{C}_{2} \mathrm{H}_{2}$ in $\mathrm{NH}_{3}$ during growth was varied from 1.5 to 23.1 vol $\%$. In all samples, the carbon was deposited for $20 \mathrm{~min}$ after pretreatment for $1 \mathrm{~h}$ in an $\mathrm{H}_{2}$ environment. When the $\mathrm{C}_{2} \mathrm{H}_{2}$ concentration was 1.5 vol $\%$, only tangled CNTs with a low growth rate were observed (Fig. 2a). This tangled CNT would result from an insufficient supply of carbon for the
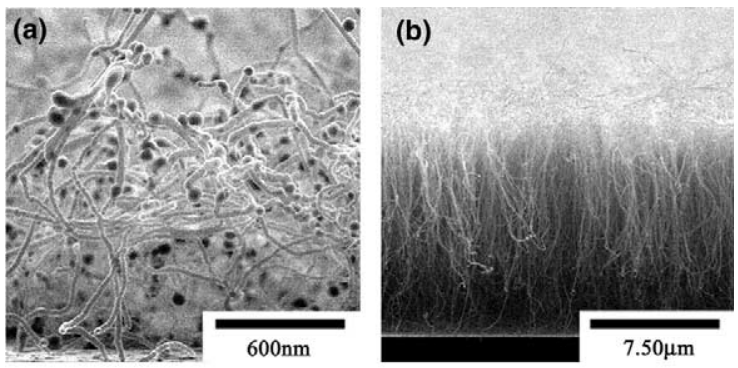

(c)
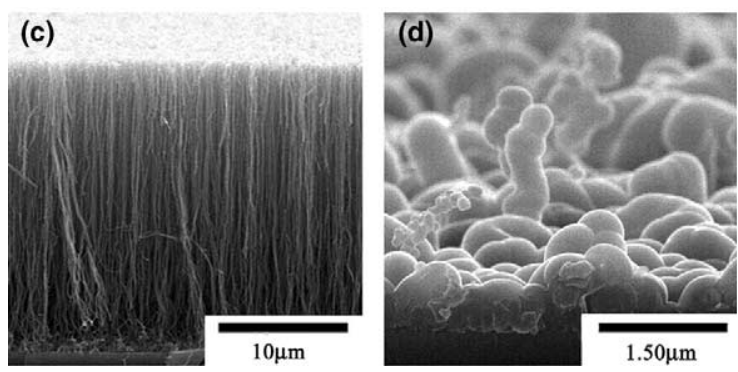

Fig. 2. SEM microstructures of the carbon deposited at $950{ }^{\circ} \mathrm{C}$ for $20 \mathrm{~min}$ after pretreatment for $1 \mathrm{~h}$ in an $\mathrm{H}_{2}$ environment when using (a) a 1.5 vol $\% \mathrm{C}_{2} \mathrm{H}_{2}+\mathrm{NH}_{3}$ environment, (b) a 5.0 vol $\% \mathrm{C}_{2} \mathrm{H}_{2}+\mathrm{NH}_{3}$ environment, (c) a $16.7 \mathrm{vol} \% \mathrm{C}_{2} \mathrm{H}_{2}+\mathrm{NH}_{3}$ environment, and (d) a 23.1 vol $\% \mathrm{C}_{2} \mathrm{H}_{2}+\mathrm{NH}_{3}$ environment during deposition.

higher growth rate. As the concentration of $\mathrm{C}_{2} \mathrm{H}_{2}$ increased, both the growth rate and the degree of alignment drastically increased, as can be seen in Fig. 2b,c. The growth rate judged from the thickness of the CNTs increased from $1.1 \mathrm{~nm} / \mathrm{s}$ at $1.5 \mathrm{vol} \%$ of $\mathrm{C}_{2} \mathrm{H}_{2}$ to $9.6 \mathrm{~nm} / \mathrm{s}$ at $16.7 \mathrm{vol} \%$ of $\mathrm{C}_{2} \mathrm{H}_{2}$. However, when the $\mathrm{C}_{2} \mathrm{H}_{2}$ concentration was larger than about $20 \mathrm{vol} \%$, excess carbon supply seemed to passivate the catalyst surface resulting in amorphous carbon deposition, as shown in Fig. 2d. Chhowalla et al. [18] reported the similar CNT deposition behavior in DC plasma CVD process. As $\mathrm{C}_{2} \mathrm{H}_{2}$ fraction in $\mathrm{NH}_{3}$ increased from $5 \%$ to $30 \%$, the growth rate rises by $30 \%$. However, the nanotubes become obelist-like beyond $30 \%$ of $\mathrm{C}_{2} \mathrm{H}_{2}$ fraction.

The composition of the deposited carbon in Fig. 2 was analyzed by X-ray photoelectron spectroscopy (XPS) and Auger spectroscopy. Before the analysis, the sample was cleaned by an Ar ion beam in the analysis chamber to remove surface contaminants. Fig. 3 summarizes the nitrogen content in the deposited carbon measured by Auger spectroscopy. Nitrogen concentration in the 


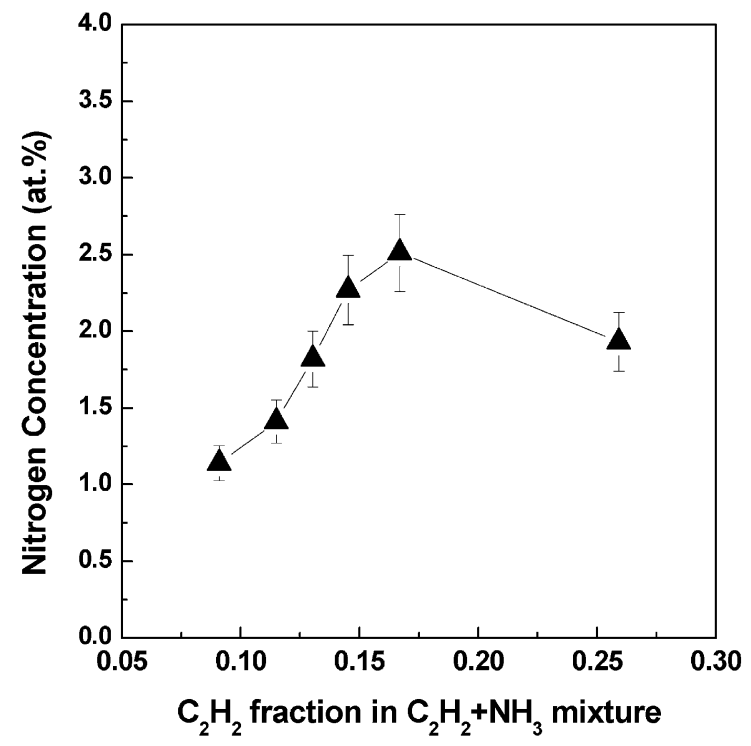

Fig. 3. Nitrogen concentration in the CNTs measured by Auger spectroscopy for various $\mathrm{C}_{2} \mathrm{H}_{2}$ concentrations in an $\mathrm{NH}_{3}$ environment.

CNT increased from 1.0 to 2.5 at.\% as the $\mathrm{C}_{2} \mathrm{H}_{2}$ concentration increased from 8 to $16.7 \mathrm{vol} \%$. In the amorphous carbons deposited when the $\mathrm{C}_{2} \mathrm{H}_{2}$ concentration was larger than about $20 \mathrm{vol} \%$, nitrogen concentration was slightly reduced. This compositional variation would be surprising if one considers that the $\mathrm{NH}_{3}$ fraction in the reaction gas decreases with increasing $\mathrm{C}_{2} \mathrm{H}_{2}$ fraction. However, the nitrogen concentration in CNT increased with increasing CNT growth rate and the degree of alignment, which exhibits an intimate relationship between CNT growth and nitrogen incorporation. Fig. 4 shows typical XPS spectra of carbon and nitrogen in the CNTs. The $\mathrm{C}_{1 \mathrm{~s}}$ peak at $285 \mathrm{eV}$ corresponds to that of graphite. The $\mathrm{N}_{1 \mathrm{~s}}$ spectrum shows two peaks at 400.9 and $398.5 \mathrm{eV}$. The high binding energy peak $(400.9 \mathrm{eV})$ is due to the nitrogen bonded to $\mathrm{sp}^{2}$ coordinated $\mathrm{C}$ atoms, i.e. substitutional $\mathrm{N}$ in the graphite sheet. The other peak at $398.5 \mathrm{eV}$ is believed to correspond to threecoordinated $\mathrm{N}$ atoms in an $\mathrm{sp}^{3}$ rich environment or at peripheries of the graphite sheet $[19,20]$. The XPS analysis shows that the nitrogen in the CNT is chemically bonded with the carbon atoms of the graphitic basal plane.

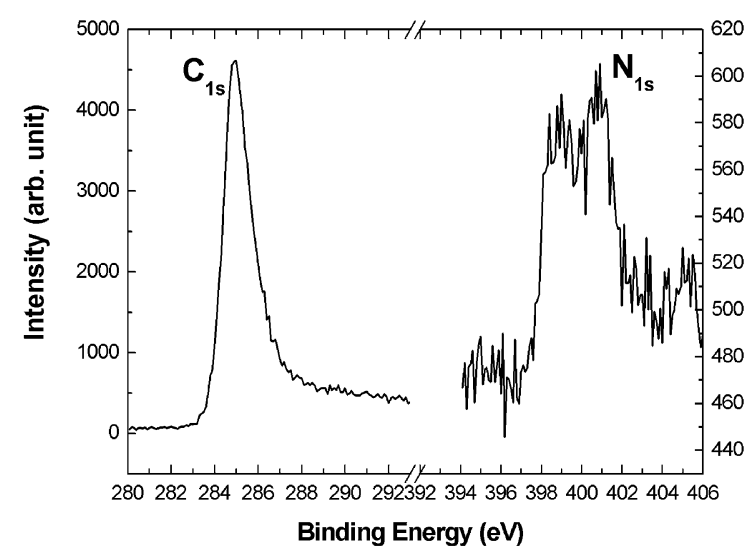

Fig. 4. X-ray photoelectron spectra of $\mathrm{C}$ and $\mathrm{N}$ of the CNTs deposited at $950{ }^{\circ} \mathrm{C}$ for $20 \mathrm{~min}$ in a $16.7 \mathrm{vol} \% \mathrm{C}_{2} \mathrm{H}_{2}+\mathrm{NH}_{3}$ environment after pretreatment in an $\mathrm{H}_{2}$ environment.

Morphological change of the graphitic basal plane due to nitrogen incorporation has been widely investigated since the theoretical prediction of a super hard $\mathrm{C}_{3} \mathrm{~N}_{4}$ phase [21]. An ab initio total energy calculation showed that the strain energies of rolling the $\mathrm{CN}$ sheets into tubular form are smaller than that for a graphite sheet [22]. A semiempirical total energy calculation also showed that nitrogen incorporation promotes the pentagons, leading to curving of the basal plane [23]. Several experimental results support the theoretical calculations. Atomic scale EELS analysis of nano onions in $\mathrm{CN}_{x}$ thin film [24] and a $\mathrm{CN}_{x}$ nanotube [17] showed that nitrogen concentration increases as the curvature of the graphitic layer increases. Hence, these result strongly suggested that nitrogen incorporation to the CNT would reduce the strain energy required to form a tubular graphitic layer. The reduced strain energy would in turn enhance the nucleation rate of the graphitic layer on the curved catalyst surface [25]. Further CNT growth also requires continuous deposition of the tubular graphitic layer, where nitrogen incorporation can reduce the strain energy.

\section{Conclusion}

The most significant result of the present work is to show that the enhanced CNT growth in an $\mathrm{N}_{2}$ 
or $\mathrm{NH}_{3}$ environment is due to nitrogen incorporation into the CNT wall or cap. Because nitrogen incorporation can reduce the strain energy required for the tubular graphitic layer of CNTs, nitrogen incorporation will decrease the activation energy for both the nucleation of the graphitic layer on the curved catalyst surface and the structural evolution of the CNT during growth. Pretreatment of the catalyst in a nitrogen environment is not a prerequisite for the enhancement of CNT growth.

\section{Acknowledgements}

This work was financially supported by the Korea Science and Engineering Foundation through the Center for Advanced Plasma Surface Engineering. KHO gratefully acknowledges partial support from the BK 21 program at Seoul National University.

\section{References}

[1] T.W. Ebbesen (Ed.), Carbon Nanotubes: Preparation and Properties, CRC Press, Boca Raton, FL, 1997.

[2] M.S. Dresselhaus, G. Dresselhaus, P.C. Eklund, Science of Fullerenes and Carbon Nanotubes, Academic, New York, 1996.

[3] W.B. Choi, Y.W. Jin, H.Y. Kim, S.J. Lee, M.J. Yun, J.H. Kang, Y.S. Choi, N.S. Park, N.S. Lee, J.M. Kim, Appl. Phys. Lett. 78 (2001) 1547.

[4] W.A. de Heer, A. Châtelain, D. Ugarte, Science 270 (1995) 1179.

[5] S.C. Tsang, J.B. Claridge, M.L.H. Green, Catal. Today 23 (1995) 3.
[6] J. Gavillet, A. Loiseau, C. Journet, F. Willaime, F. Ducastelle, J.-C. Charlier, Phys. Rev. Lett. 87 (2001) 275504.

[7] C.J. Lee, J. Park, Appl. Phys. Lett. 77 (2000) 3397.

[8] C. Bower, O. Zhou, W. Zhu, D.J. Werder, S. Jin, Appl. Phys. Lett. 77 (2000) 2767.

[9] M.H. Kuang, Z.L. Wang, X.D. Bai, J.D. Guo, E.G. Wang, Appl. Phys. Lett. 76 (2000) 1255.

[10] M. Okai, T. Muneyoshi, T. Yaguchi, S. Sasaki, Appl. Phys. Lett. 77 (2000) 3468.

[11] Z.F. Ren, Z.P. Huang, J.W. Xu, J.H. Wang, P. Bush, M.P. Siegal, P.N. Provencio, Science 282 (1998) 1105.

[12] M. Jung, K.Y. Eun, Y.-J. Baik, K.-R. Lee, J.-K. Shin, S.-T. Kim, Thin Solid Films 398-399 (2001) 150.

[13] C.J. Lee, D.W. Kim, T.J. Lee, Y.C. Choi, Y.S. Park, Y.H. Lee, W.B. Choi, N.S. Lee, G.-S. Park, J.M. Kim, Chem. Phys. Lett. 312 (1999) 461.

[14] K.S. Choi, Y.S. Cho, S.Y. Hong, J.B. Park, D.J. Kim, J. Euro. Ceram. Soc. 21 (2001) 2095.

[15] G.S. Choi, Y.S. Cho, S.Y. Hong, J.B. Park, K.H. Son, D.J. Kim, J. Appl. Phys. 91 (2002) 3847.

[16] M. Jung, K.Y. Eun, J.-K. Lee, Y.-J. Baik, K.-R. Lee, J.W. Park, Diam. Rel. Mater. 10 (2001) 1235.

[17] W.-Q. Han, P. Kohler-Redlich, T. Seeger, F. Ernst, M. Rühle, N. Grobert, W.-K. Hsu, B.-H. Chang, Y.-Q. Zhu, H.W. Kroto, D.R. Walton, M. Terrones, H. Terrones, Appl. Phys. Lett. 77 (2000) 1807.

[18] M. Chhowalla, K.B.K. Teo, C. Ducati, N.L. Rupesinghe, G.A.J. Amaratunga, A.C. Ferrarri, D. Roy, J. Robertson, W.I. Milne, J. Appl. Phys. 90 (2001) 5308.

[19] S. Stafström, Appl. Phys. Lett. 77 (2000) 3941.

[20] G.Y. Zhang, X.C. Ma, D.Y. Zhong, E.G. Wang, J. Appl. Phys. 91 (2002) 9324.

[21] A.Y. Liu, M.L. Cohen, Phys. Rev. B 41 (1990) 10727.

[22] Y. Miyamoto, M.L. Cohen, S.G. Louie, Solid State Commun. 102 (1997) 605.

[23] H. Sjöström, S. Stafström, M. Boman, J.-E. Sundgren, Phys. Rev. Lett. 75 (1995) 1336.

[24] Z. Czigány, I.F. Brunell, J. Neidhardt, L. Hultman, K. Suenaga, Appl. Phys. Lett. 79 (2001) 2639.

[25] V.L. Kuznetsov, A.N. Usoltseva, A.L. Chuvilin, E.d. Obraztsova, J.-M. Bonard, Phys. Rev. B 64 (2001) 235401. 